\title{
Effect of exogenous surfactant therapy on levels of pulmonary surfactant proteins $A$ and $D$ in preterm infants with respiratory distress syndrome
}

\author{
Young Min Bae ${ }^{1}$, Chong-Woo Bae ${ }^{1, *}$, Myung Ho \\ $\mathrm{Oh}^{2}$, Sang Han Lee ${ }^{3}$, Kee Min $\mathrm{Woo}^{3}$ and Keum \\ Bun Jung ${ }^{3}$ \\ ${ }^{1}$ Department of Pediatrics, College of Medicine, \\ Kyunghee University, Seoul 134-727, Korea \\ 2 Department of Pediatrics, College of Medicine, \\ Soonchunhyang University, Cheonan 330-721, Korea \\ ${ }^{3}$ Department of Biochemistry, College of Medicine, \\ Soonchunhyung University, Cheonan 330-721, Korea
}

\begin{abstract}
Objectives: To examine whether exogenous pulmonary surfactants (exPS) substitute for or merely supplement endogenous pulmonary surfactants (enPS) by looking at sequential changes in the surfactant proteins (SP) SP-A and SP-D in alveolar pools.

Methods: Fourteen preterm infants with RDS treated with an artificial surfactant were compared to five normalterm infants without RDS who were treated with artificial ventilation at birth.

Results: Immediately after birth, SP-A and SP-D were essentially absent in the alveolar pools of the RDS group, but were present at normal levels in the controls. Treatment with exPS apparently stimulated enPS production. Conclusions: In infants who responded well to exPS therapy, the SP concentration reached essentially normal levels within 48-72 $\mathrm{h}$ after birth.
\end{abstract}

Keywords: Endogenous pulmonary surfactants; exogenous pulmonary surfactants; surfactant proteins.

\section{Introduction}

Infants with RDS are deficient in endogenous pulmonary surfactant (enPS), i.e., all forms of surfactant protein (SP):

\footnotetext{
${ }^{*}$ Corresponding author:

Chong-Woo Bae, MD, PhD

Department of Pediatrics

College of Medicine

Kyunghee University

East-West Neo Medical Center

149 Sangil-dong

Kangdong-ku

Seoul 134-727

Korea

Tel.: $+82-2-440-6130$

Fax: + 82-2-440-7175

E-mail: baecw@khnmc.or.kr
}

SP-A, SP-B, SP-C, and SP-D. Artificial exogenous pulmonary surfactant (exPS) preparations (e.g., Surfacten ${ }^{\circledR}$, Curosurf $^{\circledR}$, Survanta ${ }^{\circledR}$, Infasurf ${ }^{\circledR}$, Alveofact $^{\circledR}$ ) are derived from extracts of animal lungs, containing SP-B and SPC, but do not SP-A or SP-D [6]. Therefore, changes in the concentration of the endogenously synthesized SP$A$ and SP-D can be used as an indicator of enPS secretion. Better understanding of the point in exPS treatment at which the insufficient enPS begins to be secreted and maintained is important for the optimal design of RDS therapy. The purpose of this study was to analyze the course of exPS treatment in preterm RDS infants and to identify the time at which enPS secretion begins. We also examined sequential changes in the concentrations of SP-A and SP-D in alveoli pools to determine whether sufficient amounts of enPS were secreted in the RDS group (which received exPS treatment) as compared to a nonRDS group.

\section{Patients and methods}

The infants were treated in the neonatal intensive care units at Kyunghee University Hospital and Soonchunhyang University Chonan Hospital between March 2004 and August 2004. The RDS group consisted of 14 preterm infants (gestational period: median 30 weeks +3 days, range 25 weeks + 5 days $\sim 33$ weeks +2 days, birth weight: median $1010 \mathrm{~g}$, range $720 \sim 1750 \mathrm{~g}$ ) who were ventilated for RDS without antenatal steroid treatment and were treated with an intra-tracheal instillation of the exPS Surfacten ${ }^{\circledR}$, which is a modified bovine PS preparation made from bovine lung PS and synthetic PL (Mitsubishi Pharma Co., Japan). A single dose of Surfacten ${ }^{\circledR}$ was given within $3 \mathrm{~h}$ after birth in all cases of the RDS group. We selected a control group (non-RDS) of full term newborns with a normal physiological pool of SP. This group consisted of five full term infants who were ventilated for central hypoventilation due to perinatal asphyxia without primary lung pathology and, therefore, did not receive exPS treatment.

\section{Collection and preparation of bronchoalveolar lavage samples}

Bronchoalveolar lavage (BAL) was carried out essentially as previously described [15]; samples were taken by using the standardized distal wedge-catheter newborn BAL technique at 0, 24, 48 , and $72 \mathrm{~h}$ after birth in both the RDS and non-RDS groups. The infant was in the supine position with the face turned to the left, and the oxygen saturation was maintained above $95 \%$. An F6-sized suction catheter was inserted through the intratracheal 
tube, and normal saline $(1 \mathrm{~mL} / \mathrm{kg})$ was infused and then aspirated immediately using a suction device. This procedure was then repeated once. The supernatant was centrifuged at $500 \times g$ for $5 \mathrm{~min}$ and stored at $-70^{\circ} \mathrm{C}$. For analysis, the supernatant was mixed with $15 \mathrm{~mL}$ of BNC buffer (10 mM sodium borate, $\mathrm{pH}$ 7.4; $150 \mathrm{mM} \mathrm{NaCl}, 3 \mathrm{mM} \mathrm{CaCl}_{2}$ ) and centrifuged successively at $500 \times g$ for $10 \mathrm{~min}$ at $4^{\circ} \mathrm{C}$ and at $27000 \times g$ for $2 \mathrm{~h}$. After adding BNC $100 \mu \mathrm{L}$ to the precipitate mix, it was stored at a temperature of $-20^{\circ} \mathrm{C}$

\section{Gel electrophoresis and immunoblot analysis}

Samples were analyzed by SDS-polyacrylamide gel electrophoresis using 12\% NuPAGE Novex Bis-Tris gels with the XCell SureLock Mini-Cell (Invitrogen Life Technologies, Carlsbad, CA). Proteins were then transferred from the gel to nitrocellulose membranes, which were blocked for $1 \mathrm{~h}$ with PBS plus $0.5 \%$ BSA and $0.02 \%$ Tween 20 (Sigma, St. Louis, MO). SP-A and SP-D were detected with antibodies from Santa Cruz Inc. (Delaware, CA); membranes were incubated with primary antibodies at 1:500 in PBS at $4^{\circ} \mathrm{C}$ overnight. Blots were incubated with peroxidase-conjugated secondary antibodies at 1:1000 in PBS for $1 \mathrm{~h}$ at $4^{\circ} \mathrm{C}$ and were developed using the Enhanced Chemiluminescence Detection System (Amersham Bioscience, Buckinghamshire, England).

\section{Statistical analysis}

Statistics were analyzed by using the SPSS 12.0 statistical package; the two-tailed Student's $t$-test and the Mann-Whitney test were used for statistical comparisons. $\mathrm{P}<0.05$ were considered to be statistically significant.

\section{Results}

\section{Analysis of SP-A and SP-D concentrations} in the RDS and non-RDS groups

In the RDS group, SP-A and SP-D were either absent or were only minimally present at birth. However, concentrations of SP-A and SP-D (as assessed by densitometer units obtained from quantitative immunoblot analysis) in the non-RDS group were significantly higher than those of the RDS group $(P<0.01)$. Figure 1 shows the mean densitometry units obtained from a single SDS PAGE panel of five cases in both the RDS and non-RDS groups.

We also used immunoblot analysis to examine SP-A and SP-D expression at 0, 24, and $48 \mathrm{~h}$ after birth in the RDS and non-RDS groups (Figure 2). Because the RDS group received a dose of exPS within $3 \mathrm{~h}$ after birth, we expected to see increased SP levels after $3 \mathrm{~h}$. In the RDS group, the level of both SP-A and SP-D was deficient at $0 \mathrm{~h}$ after birth, whereas in the non-RDS group, the level was sufficient even at $0 \mathrm{~h}$ after birth.

\section{Sequential increases in the ratio of SP-A and SP-D concentrations in the RDS and non-RDS group}

Figure 3 shows the sequential changes in the ratio of SP$A$ and SP-D concentrations, as analyzed by densitometry of immunoblot samples. The level of SP-A and SP-D in the RDS group at $\mathrm{O} \mathrm{h}$ after birth was arbitrarily set at one to provide a basis for the comparison; data are presented as a ratio of (units of SP-A or SP-D at $\mathrm{x} h$ after birth)/ (units of SP-A or SP-D at $0 \mathrm{~h}$ after birth). In the 14 subjects in the RDS group, there was a significant increase in the relative SP-A abundance at $72 \mathrm{~h}$ after birth; SP-A levels at this time point were similar to those of the nonRDS group at $72 \mathrm{~h}(\mathrm{P}<0.01)$. Levels of SP-D increased notably at the $48 \mathrm{~h}$ time point and reached concentrations similar to those of the non-RDS group at $72 \mathrm{~h}$. For the non-RDS group, levels of SP-A and SP-D were significantly higher than those in the RDS group starting at $0 \mathrm{~h}$ after birth; this difference was maintained continuously after birth.

\section{Discussion}

In human infants, the size of the PS pool can be estimated by the dilutional isotope method, in which an isotope-labeled PS component is introduced into the body to track PS levels and estimates of the pool size are made by assessing the amount of dilution of the isotope.
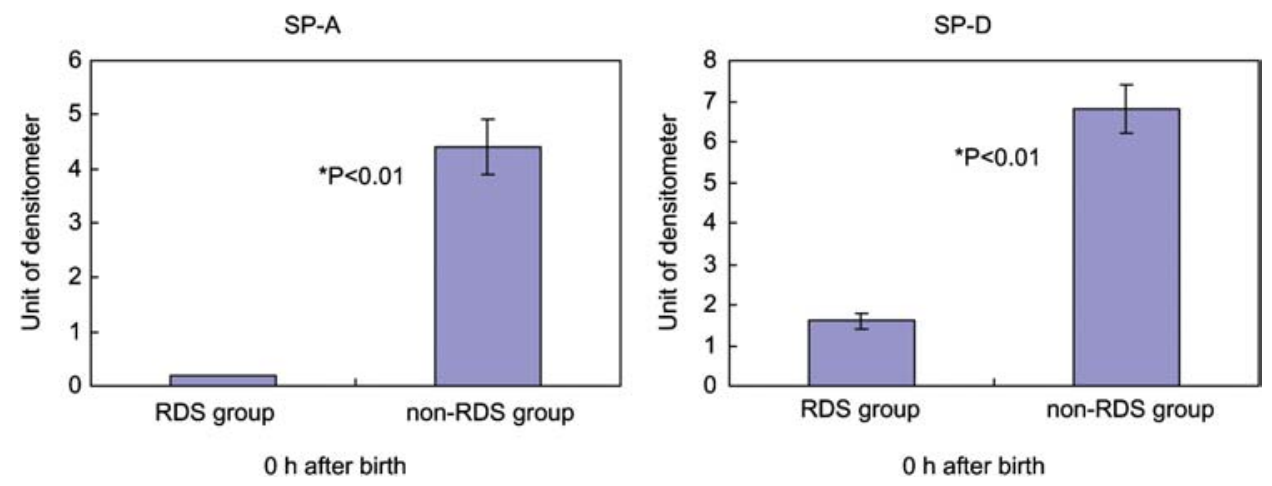

Figure 1 Comparison of surfactant protein SP-A (left) and D (right) densitometer in bronchoalveolar fluid of RDS group ( $n=5)$ and control group $(n=5)$ at $\mathrm{O}$ h after birth measured by the Western blot analysis with densitometer. Unit: unit of densitometer. 
SP-A

$0 \mathrm{~h}$

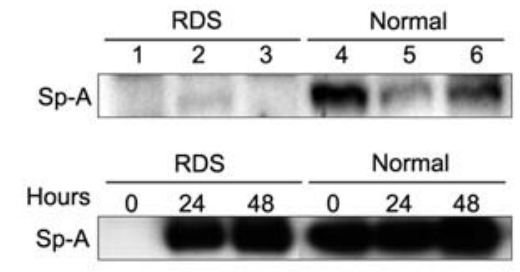

SP-D

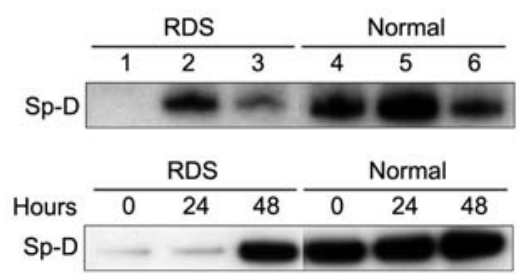

Figure 2 Expression examples of SP-A (left) and D (right) by the Western blot analysis in RDS group ( $n=3$ ) and non-RDS group $(\mathrm{n}=3)$ at $0,24,48 \mathrm{~h}$ after birth.

SP-A

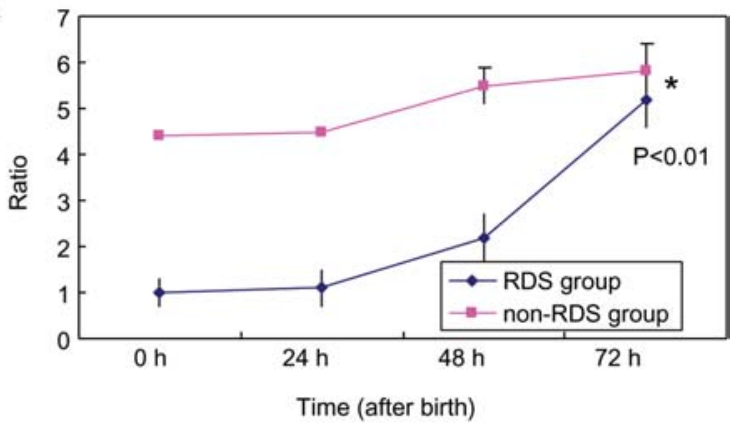

SP-D

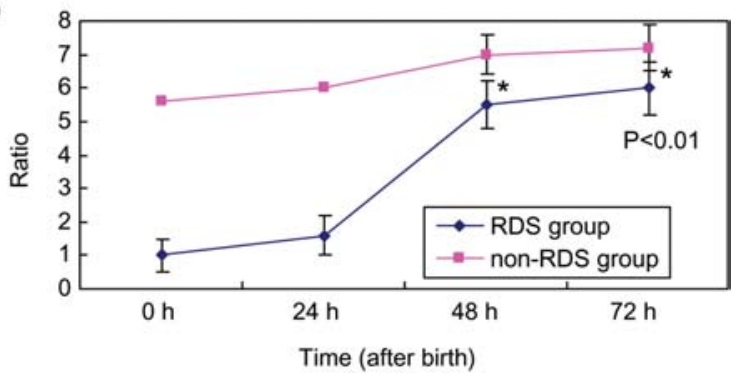

Figure 3 Sequential changes of increasing ratio SP-A and D in RDS group $(n=14)$ and non-RDS group $(n=5)$ after birth. Unit means increasing ratio comparing the unit at $0 \mathrm{~h}$ as one after birth in RDS group. ${ }^{*} \mathrm{P}<0.01$.

In mothers, the PS pool size increases in late pregnancy, then gradually decreases after birth to the normal postpartum adult level [18]. In preterm infants with RDS, the PS pool is very low (2-10 mg PL/kg body weight) because of lung immaturity, especially of type II pneumocytes [14]. Hallman et al. [11] and Griese et al. [9] used the isotopic dilution method to measure PL in preterm infants with RDS and demonstrated an apparent pool size of $\sim 16 \mathrm{mg}$ PL/kg. Another study measured pool size in preterm infants with RDS by using an endotracheally administered stable isotope in combination with a treatment dose of surfactant (100 mg PL/kg), and found that the endogenous PS PL pool size (before treatment) was $\sim 10 \mathrm{mg}$ PL/kg [16]. Several studies examining the kinetics of PS synthesis showed that in both human and animal infants with RDS, rates of PS synthe- sis were low $[2,4,5]$. Animal studies showed a slower rate of PS turnover in newborns as compared to adults, and in human studies using stable isotopes, the surfactant PL metabolism was slower in preterm infants with RDS compared to term infants without lung diseases. Taken together, the results of these studies suggested that in preterm infants with RDS, the small alveolar PS pool size, decreased rates of PS synthesis, and decreased PS turnover rates could affect the pathogenesis of the disease [8-10].

In RDS cases, enPS is deficient at birth; therefore, the infants have insufficient PS and SP in their alveolar pool. There are many commercially available exPS preparations that may supplement the insufficient enPS at birth. We used a modified bovine surfactant, Surfacten ${ }^{\circledR}$, as an artificial exPS replacement therapy in preterm infants with RDS. Surfacten ${ }^{\circledR}$ was developed by Fujiwara et al. [8] in 1980, and used in 1990 [7]. Surfacten ${ }^{\circledR}$, which is a mixture of natural PS (extracted from bovine lung) and artificial PLs, has only SP-B and SP-C and lacks SP-A and SP-D. When Surfacten ${ }^{\circledR}$ is administered to RDS infants, their SP is different from non-RDS infants who have all four SPs in the endogenous alveolar pool. Thus, monitoring the concentration of SP-A and D in the alveolar pool can be used as an indicator of enPS secretion.

In this study, we found that infants in the RDS group were deficient for PS, and a very notable difference in the RDS levels of PS vs. those of the non-RDS group was seen. Our data also suggested that exPS might stimulate the production of SP-A and SP-D in the RDS group (treated with artificial surfactants $3 \mathrm{~h}$ after birth). Although the administration of exPS is routine for treatment of RDS in preterm infants, there is little information regarding the effects of exPS on enPS metabolism. A study of exPS administration in animals found that it stimulated enPS synthesis and increased PS pool size [3]. In a human study that measured the concentration of SP-A and SP$D$ in BAL fluid in preterm infants with RDS, data showed that levels of SP-A and SP-D increased after treatment with artificial exPS [13]. Since the exPS used in the treatment did not contain SP-A, the data suggest that perhaps the secretion of enPS, which contains SP-A was stimulated by the administration of exPS. 
Other studies showed that in preterm infants, the incorporation of ${ }^{13} \mathrm{C}$ in the form of intravenous $\left[\mathrm{U}-{ }^{13} \mathrm{C}\right.$ ] glucose into the alveolar PS phosphatidylcholine and palmitate increased after treatment with artificial exPS [3, 10]. Results from our study suggest a similar finding: both SP-A and SP-D were absent in the alveolar pools of the RDS group immediately after birth, but concentrations of SP-A and D increased after treatment with an exPS preparation (without SP-A and SP-D). This supports the conclusion that exPS treatment in preterm infants with RDS seems to stimulate enPS synthesis and secretion. Additionally, because the mechanism that is believed to function in the recycling of PS involves the uptake of PS components by type II pneumocytes [12] for degradation and recycling into newly synthesized PS lipids or proteins [17], we could also speculate that exPS administration stimulates recycling of PS as well as de novo synthesis.

The timing of enPS secretion after exPS therapy is an important consideration in planning the optimal timing for such therapy, but there have been few studies in either humans or animals that examined this factor. Beresford and Shaw [1] reported that concentrations of SP-A and SP-D in BAL increased significantly at day 4 and day 7 in preterm infants who were ventilated for RDS and were treated with natural and synthetic PSs. In this study, we similarly saw that the enPS components SP-A and SP$D$, which were not present in the artificial PS administered for treatment, were fully secreted in the alveolar pool at 48-72 $\mathrm{h}$ after birth. We can infer that there was a very close relation between the clinical course observed after treatment of RDS and results of this study (data was not shown). Taken together, the data showed that the amount of enPS in infants with RDS was clearly insufficient at birth, but seemed to be stimulated and improved after treatment with exPS. Also, there are substantial improvements in the alveolar pools of PS at 48-72 h after birth.

\section{References}

[1] Beresford MW, Shaw NJ. Bronchoalveolar lavage surfactant protein $A, B$, and $D$ concentrations in preterm infants ventilated for respiratory distress syndrome receiving natural and synthetic surfactants. Pediatr Res. 2003;53: 663-70.

[2] Bohlin K, Merchak A, Spence K, Patterson BW, Hamvas A. Endogenous surfactant metabolism in newborn infants with and without respiratory failure. Pediatr Res. 2003;54: 185-91.

[3] Bunt JE, Carnielli VP, Janssen DJ, Wattimena JL, Hop WC, Sauer PJ, et al. Treatment with exogenous surfactant stimulates endogenous surfactant synthesis in premature infants with respiratory distress syndrome. Crit Care Med. 2000;28:3383-8.
[4] Bunt JE, Zimmermann LJ, Wattimena JL, van Beek RH, Sauer PJ, Carnielli VP. Endogenous surfactant turnover in preterm infants measured with isotopes. Am J Respir Crit Care Med. 1998;157:810-9.

[5] Cavicchioli P, Zimmermann LJ, Cogo PE, Badon T, Giordano $\mathrm{G}$, Torresin M, et al. Endogenous surfactant turnover in preterm infants with respiratory distress syndrome studied with stable isotope lipids. Am J Respir Crit Care Med. 2001;163:55-60.

[6] Dekowski SA, Hoitzman RB. Surfactant replacement therapy. An update on applications. Pediatr Clin North Am. 1998;45:549-72.

[7] Fujiwara T, Konishi M, Chida S, Okuyama K, Ogawa $Y$, Takeuchi $Y$, et al. Surfactant replacement therapy with a single postventilatory dose of a reconstituted bovine surfactant in preterm neonates with respiratory distress syndrome: final analysis of a multicenter, double-blind, randomized trial and comparison with similar trials. Pediatrics. 1990;86:753-64.

[8] Fujiwara T, Maeta H, Chida S, Morita T, Watabe Y, Abe T. Artificial surfactant therapy in hyaline-membrane disease. Lancet. 1980;1:55-9.

[9] Griese M, Dietrich P, Reinhardt D. Pharmacokinetics of bovine surfactant in neonatal respiratory distress syndrome. Am J Respir Crit Care Med. 1995;152:1050-4.

[10] Haagsman HP, Diemel RV. Surfactant-associated proteins: functions and structural variation. Comp Biochem Physiol A Mol Intergr Physiol. 2001;129:91-108.

[11] Hallman M, Merritt TA, Pohjavuori M, Gluck L. Effect of surfactant substitution on lung effluent phospholipids in respiratory distress syndrome: evaluation of surfactant phospholipid turnover, pool size, and the relationship to severity of respiratory failure. Pediatr Res. 1986;20: 1228-35.

[12] Jacobs $H$, Jobe A, Ikegami M, Conaway D. The significance of reutilization of surfactant phosphatidylcholine. $J$ Biol Chem. 1983;258:4159-65.

[13] Jobe AH. Pulmonary surfactant therapy. N Engl J Med. 1993;328:861-8.

[14] Jobe AH, Ikegami M. Biology of surfactant. Clin Perinatol. 2001;28:655-69.

[15] Kotecha S. Bronchoalveolar lavage of newborn infants. Pediatr Pulmonol. 1999;18(Suppl):122-4.

[16] Torresin M, Zimmermann LJ, Cogo PE, Cavicchioli P, Badon T, Giordano G, et al. Exogenous surfactant kinetics in infant respiratory distress syndrome: A novel method with stable isotopes. Am J Respir Crit Care Med. 2000; 161:1584-9.

[17] Wright JR, Dobbs LG. Regulation of pulmonary surfactant secretion and clearance. Annu Rev Physiol. 1991;53: 395-414.

[18] Zimmermann LJ, Janssen DJ, Tibboel D, Hamvas A, Carnielli VP. Surfactant metabolism in the neonate. Biol Neonate. 2005;87:296-307.

The authors stated that there are no conflicts of interest regarding the publication of this article.

Received December 11, 2008. Revised March 19, 2009. Accepted April 3, 2009. Previously published online June 3, 2009. 